\title{
Knowledge integration in multi-agent decision support system for financial e-services
}

\author{
Marcin Hernes \\ Wrocław University of Economics \\ ul. Komandorska 118/120, 53-345 Wrocław, Poland \\ Email: marcin.hernes@ue.wroc.pl
}

\begin{abstract}
Providing financial e-services in the all areas involves taking decisions processes. Existing systems, also multi-agent systems, usually include only one of the earlier mentioned areas, and they are closed systems, available only to a small group of users. In addition, agents' knowledge in these systems is characterized by a certain degree of heterogeneity. Since in the decisive process one final decision is required, knowledge shall be automatically integrated. The aim of this paper is presentation of the author's method for knowledge integration in multi-agent decision support system of financial e-services. The first part of paper presents an architecture of the developed system, functioning of selected agents and a structure of agents' knowledge representation. Next, the developed method for integration of knowledge has been described. The last part of paper presents the results of research experiment to evaluate the effectiveness of the system and the developed method.
\end{abstract}

\section{INTRODUCTION}

$I_{n}^{N}$ $\mathrm{N}$ the era of e-economy one can observe a sudden increase in the level of offered e-services connected with finances, embracing all financial services available to clients via the Internet [1]. The Polish Agency for Enterprise Development [2] has defined financial e-services as all operations connected with finances conducted via electronic media. These types of services are provided within the following areas $[2,3,4]$ :

- investment (securities, currencies),

- banking,

- insurance,

- financial consulting,

- managing one's own finances,

- payments.

Providing financial e-services in the mentioned areas involves taking decisions processes. These processes most often need to be executed in a near-real time, and they are always characterized by a certain degree of risk. They are often supported by multi-agent decision support system [5]. Such system may generate decisions constituting hints or tips to investors, or alternatively decisions may be taken automatically (taking into account criteria specified by an investor - e.g. return rate, risk). However, existing systems

\author{
Jadwiga Sobieska-Karpińska \\ The Witelon State University of Applied \\ Sciences in Legnica, \\ Sejmowa 5A, 59-220 Legnica, Poland \\ Email: jadwiga.sobieska.karpinska@gmail.com
}

usually include only one of the earlier mentioned areas, and they are closed systems, available only to a small group of users. It needs to be noticed that in multi-agent decision support system, agents use various sources of data and different methods of supporting decisions. Consequently, variants of decisions presented by individual agents may differ. Therefore, agents' knowledge is characterized by a certain degree of heterogeneity. Since in the decisive process one final decision is required, knowledge shall be automatically integrated. The integration shall be performed in relation to a given area, and also in relation to all areas financial e-services are provided.

Related works on the subject also mention various methods of knowledge integration, for example negotiations [6], or deduction-calculation methods [7]. Negotiations enable effective integration of knowledge by reaching a compromise, however they require exchanging a large number of communications between agents, which results in decreased efficiency of the multi-agent system. The deduction-calculation methods (e.g. ones based on the theory of games, classical mechanics, or methods of choice) enable one to obtain a great computational or calculation capacity of a system, however they do not guarantee a proper result of knowledge integration [8]. Thus, applying negotiation or deduction and calculation methods cannot guarantee an adequate level of satisfaction from taken decisions. In order to eliminate the presented problems, consensus methods may be applied which enable integration of knowledge in a real time and guarantee reaching a good compromise at a lower level of risk, which may consequently lead to selecting decisions producing profits satisfactory for a decision maker $[8,9]$. In a consensus each party/side is taken into account, each party "loses" the least, and each one contributes to the consensus, and all parties accept the consensus, so the consensus constitutes a representation of all agents.

The aim of this paper is presentation of the author's method for knowledge integration in multi-agent decision support system for financial e-services. The first part of paper presents an architecture of the developed system, functioning of selected agents and a structure of agents' knowledge representation. Next, the developed method for integration of knowledge has been described. The last part of paper presents the results of research experiment to evaluate the effectiveness of the system and the developed method. 


\section{ARCHITECTURE OF SYSTEM AND DESCRIPTION OF SELECTED AGENTS}

Multi-agent decision support system for financial eservices consist of following elements:

1. Collectives of agents. The purpose of the members of the collective is the analysis of information from the market, generating a decision and taking an action. Each agent in the collective running on the basis of a different method of decision support. Each collective makes decisions from a different area (for example, Collective 1 makes the banking decisions, Collective 2 makes the investment decisions, Collective 3 makes the insurance decisions). Collective members knowledge state is represented by uniform structure (described in section V).

2. Knowledge integration module, which integrate the knowledge of individual members of the collectives (by using a consensus method - integration is performed independently for each collective). One, final decision is determined (for each collective determined a separate decision). The final decision is then presented to users.

3. Users - financial investors or software agents making decisions on behalf of the investor.

In our prototype of system, agents running in order to determine decisions in the area of investment and banking use methods of technical analysis, fundamental analysis, artificial intelligence (such as genetic algorithms, artificial neural networks, expert systems), two collectives : financial investments and banking. The next part of paper describes functioning of randomly selected agents: MixedTechnical, BollingerPlus and Fundamental.

\section{A. . The MixedTechnical agent}

MixedTechnical agent has been developed on the Java Agent Development Framework (JADE), which is a platform to facilitate the creation of agents and multi-agent systems in the Java programming language [10]. Agent generates buy/sell decisions on the basis of commonly used technical analysis indicators (Lento, 2008): Average Directional Index (ADX), Relative Strenght Index (RSI), Rate of Change (ROC), Commodity Channel Index (CCI), Moving Average of Oscillator (OsMA), Moving Average Convergence Divergence (MACD), Stop and Reverse (SAR), Williams \%R, Moving Average (MA). Agent generates decisions depending on what the decision is suggested by a larger number of indicators used. Agent's knowledge is represented by using three-values logic (value „1" denotes „buy” decision, value ,-1" denotes ,sell”, decision, value ,0” denotes ,do nothing”).

\section{B. . The BollingerPlus agent}

The BollingerPlus agent is created on the basis of the Bollinger Bands indicator [11]. These bands are volatility constraints placed above and below a moving average. Volatility is expressed by the standard deviation, which changes as volatility increases and decreases.

The bands automatically widen when volatility increases and narrow when volatility decreases. The buy decision's probability level is calculated when the price is close to the upper Bollinger Band or breaks above it, and the sell decision is calculated when the price is close to the lower Bollinger Band or falls below it.

\section{The Fundamental agent}

Agent Fundamental makes decisions using fundamental analysis. For this purpose he performs the analysis of text documents ${ }^{1}$ containing the experts' opinions on the economic situation or the organization's situation. The main purpose of the analysis is to determine the general sentiment of opinion, i.e. to determine whether the opinion is positive (suggesting a "buy" decision) or negative (suggesting a "sell" decision) or neutral (suggesting the "leave unchanged" decision). The analysis is done by the agent built by using The Learning Intelligent Distribution Agent (LIDA) architecture [12]. The advantage of this architecture is its emergent-symbolic character, making it possible to process both structured (numerical and symbolic) and unstructured (stored in natural language) information. This agent consist of following modules: sensory memory, perceptual memory, workspace, episodic memory, declarative memory, attentional codelets, global workspace, action selection, sensory-motor memory. The functioning of the agent is performed in the frame a cognitive cycle.

Considering the process of analysis of expert opinions, the environment of agent functioning is a set of text documents containing these opinions (opinions are placed e.g. on financial portals). Agent looking for opinions, and then stores them in a repository (system's database).

Text analysis is performed in the following way:

1. A semantic network containing terms and connections between them is created in the perceptual memory on the basis of a learning set. The perceptual memory stores also synonyms and different variations of words (thesaurus). In the perceptual memory of LIDA agents terms are represented by means of nodes, whereas connections are represented by means of links.

2. Individual text documents are added one by one into the sensory memory.

3. Opinions are analyzed by codelets, i.e. programs which search through texts according to certain criteria specified by means of configuration parameters.

4. Results of analysis, in the semantic network form, are transferred to the workspace (a current situational model is created).

5. In the next step, the situational model is passed to the global workspace and from the procedural memory the following patterns of action are automatically selected: „saving results of opinion analysis into a data base and ,loading next opinion into the sensory memory".

\footnotetext{
1 Text documents' analysis, performed by LIDA agent, has been characterized in work [13] in details.
} 


\section{METHOD FOR KNOWLEDGE REPRESENTATION}

Each agent running within the given collective presents its decision in the form of a specific structure of knowledge. In the considered system a structure developed by [10] has been used. The structure is definied as follows:

Definition 1

A structure for representation a decision $D$ of finite set of financial assets ${ }^{2} E=\left\{e_{1}, e_{2}, \ldots, e_{N}\right\}$ is called a sequence:

$$
D=\left\langle\left\{E W^{+}\right\},\left\{E W^{ \pm}\right\},\left\{E W^{-}\right\}, Z, S P, D T\right\rangle \text { where: }
$$

1) $E W^{+}=\left\langle e_{o}, p e_{o}\right\rangle,\left\langle e_{q}, p e_{q}\right\rangle, \ldots,\left\langle e_{p}, p e_{p}\right\rangle$.

Couple $\left\langle e_{x}, p e_{x}\right\rangle$, where: $e_{x} \in E$ and $p e_{x} \in[0,1]$ denote a financial asset and this asset's participation in set $E W^{+}$.

Financial asset $e_{x} \in\left\langle e_{x}, p e_{x}\right\rangle$ is denoted by $e_{x}^{+}$ when $\left\langle e_{x}, p e_{x}\right\rangle \in E W^{+}$. The set $E W^{+}$is called a positive set; in other words, it is a set of financial assets with respect to which an agent has the knowledge or information that they should be buy.

2) $E W^{ \pm}=\left\langle e_{r}, p e_{r}\right\rangle,\left\langle e_{s}, p e_{s}\right\rangle, \ldots,\left\langle e_{t}, p e_{t}\right\rangle$.

Couple $\left\langle e_{x}, p e_{x}\right\rangle$, where: $e_{x} \in E$ and $p e_{x} \in[0,1]$ denote a financial asset and this asset's participation in set $E W^{ \pm}$.

Financial asset $e_{x} \in\left\langle e_{x}, p e_{x}\right\rangle$ is denoted by $e_{x}^{ \pm}$ when $\left\langle e_{x}, p e_{x}\right\rangle \in E W^{ \pm}$. The set $E W^{ \pm}$is called a neutral set, in other words, it is a set of financial assets, with respect to which an agent has no knowledge or information whether to buy or sell them. If these assets are held by an investor, they should not be sold, or if they are not in the possession of the investor, they should not be bought.

3) $E W^{-}=\left\langle e_{u}, p e_{u}\right\rangle,\left\langle e_{v}, p e_{v}\right\rangle, \ldots,\left\langle e_{w}, p e_{w}\right\rangle$.

Couple $\left\langle e_{x}, p e_{x}\right\rangle$, w here: $e_{x} \in E$ and $p e_{x} \in[0,1]$, denote a financial asset and this asset's participation in set $E W^{-}$.

Financial asset $e_{x} \in\left\langle e_{x}, p e_{x}\right\rangle$ is denoted by $e_{x}^{-}$ when $\left\langle e_{x}, p e_{x}\right\rangle \in E W^{-}$. The set $E W^{-}$is called a negative set; in other words it is a set of financial assets with respect to which an agent has the knowledge or information that they should be sell.

4) $Z \in[0,1]$ - decision rate of return forecast.

\footnotetext{
2 assets including cash assets as a contractual right to receive cash assets, the right to exchange financial instruments with another entity under favorable conditions, and equity instruments issued by other entities [14].
}

5) $S P \in[0,1]$ - degree of certainty of rate $Z$. It can be calculated on the basis of the level of risk related to the decision.

6) $D T$ - date of decision.

\section{METHOD FOR KNOWLEDGE INTEGRATION}

Fig 1 presents schema of the knowledge integration process.

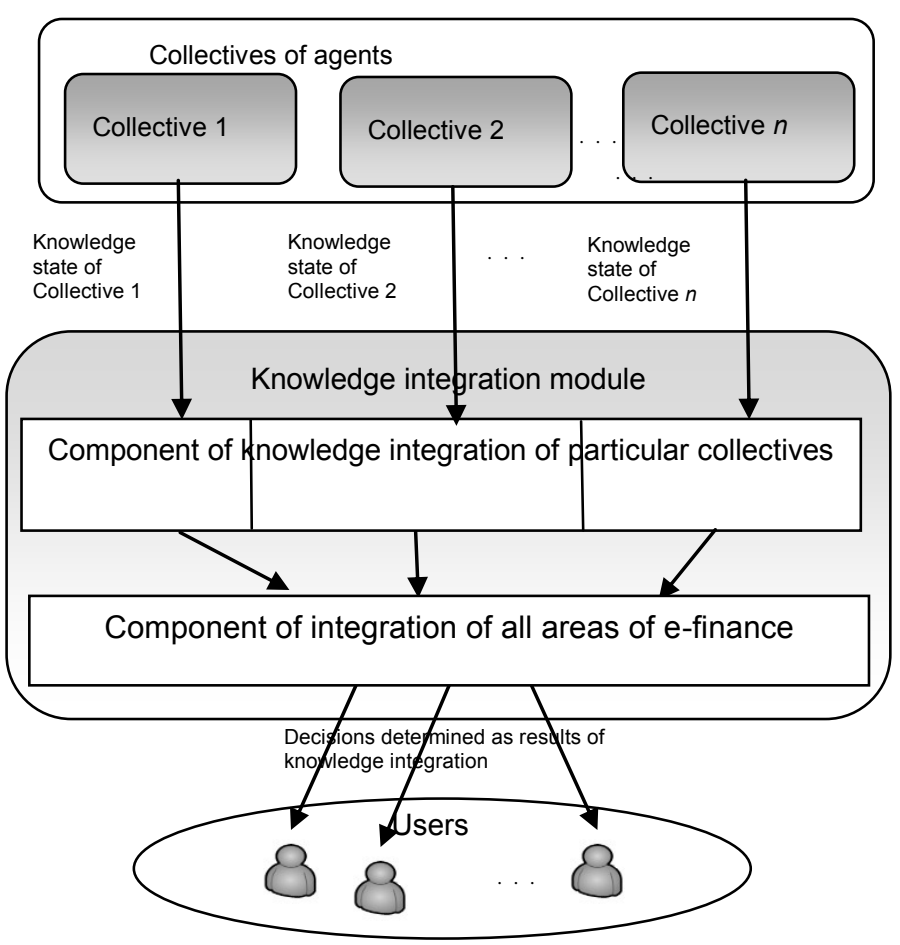

Fig. 1. Schema of the knowledge integration process

In order to knowledge integration, a consensus algorithm is used, formally defined as follows:

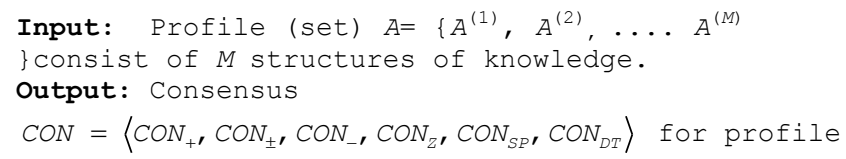




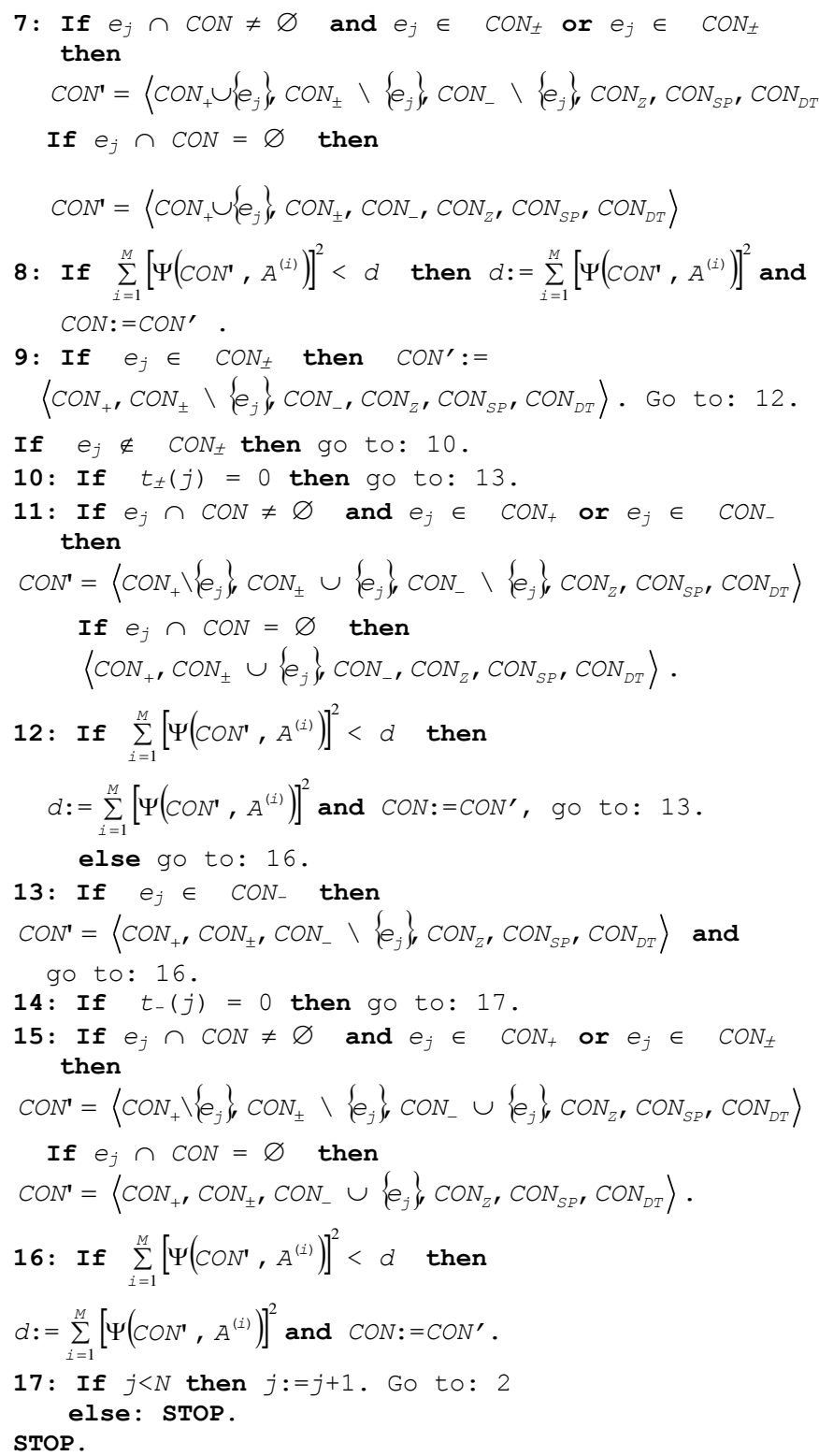

\section{V.RESEARCH EXPERIMENT}

The aim of the experiment was to examine the effectiveness of the system and developed method for knowledge integration. The collective knowledge of agents on the area of investment and knowledge integration module (named Agent Supervisor), was evaluated. Data from randomly selected quotations has been used (Sygnity company). Test was conducted, which the following assumptions:

1. Quotations from randomly selected periods was used:

- 01-02-2016 9.30 to 06-02-2016 17.00,

- 08-02-2016 9.30 to 13-02-2016 17.00,

- $15-02-20169.30$ to 20-02-2016 17.00.

2. Following agents was evaluated:

- MixedTechnical,

- BollingerPlus,

- Fundamental,
- Supervisor.

3. It was assumed that the initial capital, which has an investor is $1000 \mathrm{PLN}$, and the rate of return on investment assumed difference between that amount and the amount the investor will have the last sell transactions in a given period. The rate of return is expressed in nominal units (PLN).

4. The transaction cost was not considered.

5. It was assumed that in each transaction the investor engages $100 \%$ of the capital held.

6. Analysis of the quality of collective knowledge was carried out using the following measurement (ratios):

- rate of return (ratio $x_{1}$ ),

- the number of profitable transactions (ratio $x_{2}$ ),

- the number of unprofitable transactions (ratio $x_{3}$ ),

- the average rate of return per transaction (r. $x_{4}$ ),

- Sharpe ratio (ratio $x_{5}$ ),

- the average coefficient of variation (ratio $x_{6}$ ).

In order to comparison quality of collective knowledge, the following function was used[15]:

$$
y=\left(a_{1} x_{1}+a_{2} x_{2}+a_{3}\left(1-x_{3}\right)+a_{4} x_{4}+a_{5} x_{5}+a_{6}\left(1-x_{6}\right)\right) \text {. }
$$

where $x_{i}$ denote the normalized values of ratios mentioned in item 6 from $x_{1}$ to $x_{6}$. It was adopted in the test that coefficients $a_{1}$ to $a_{6}=1 / 6$.

7. The results obtained by the tested agents were compared with the results of the Buy-and-Hold $(\mathrm{B} \& \mathrm{H})$ benchmark ${ }^{3}$ - table 1.

Summing up the results of the evaluation of knowledge of a group of agents and the Supervisor agent one may notice that in the considered periods their decisions generated both profits as well as losses. While evaluating the efficiency of the system one needs to take into account not only the return rate but also other indicators, including the level of risk connected with an investment, which the evaluation function employed in the article enables. In the first period, BollingerPlus proved to be the best agent, and the remaining agents got a higher note than the $B \& H$ benchmark note. In the second period, the Supervisor agent received a note higher that the remaining agents and the $B \& H$ benchmark. Taking into account the third period, one may notice that the ranking of notes looks similar to the second period.

Taking into consideration all the periods one may conclude that most often ( 2 of 3 periods) the highest note was given to the Supervisor agent, even though the return rate achieved by the agent had not always been the highest one. The note however results from a low level of risk connected with investing on the basis of decisions generated as a result of knowledge integration. However, in all periods, the MixedTechnical agent received low notes as due to a relatively high level of risk it generated little return rates. The Fundamental agent received average level notes in all periods which may be connected with the fact that the agent generated a very small number of decisions.

\footnotetext{
${ }^{3}$ benchmark is also implemented as agent's algorithm.
} 
TABLE I.

RESULTS OF AGENTS PERFORMANCE ANALYSIS

\begin{tabular}{|c|c|c|c|c|c|c|c|c|}
\hline \multirow[t]{2}{*}{ Agent's name } & \multirow[t]{2}{*}{ Period } & \multirow[t]{2}{*}{$\begin{array}{c}\text { Rate of } \\
\text { return }\end{array}$} & \multicolumn{2}{|c|}{$\begin{array}{l}\text { Number of } \\
\text { transaction }\end{array}$} & \multirow{2}{*}{$\begin{array}{c}\text { Rate of return } \\
\text { per } \\
\text { transaction }\end{array}$} & \multirow[t]{2}{*}{ Sharpe ratio } & \multirow{2}{*}{$\begin{array}{c}\text { Average } \\
\text { coeffecient of } \\
\text { variation }\end{array}$} & \multirow[t]{2}{*}{$\begin{array}{l}\text { Evaluation } \\
\text { function }\end{array}$} \\
\hline & & & $\begin{array}{c}\text { profita } \\
\text { ble }\end{array}$ & $\begin{array}{c}\text { unprofita } \\
\text { ble }\end{array}$ & & & & \\
\hline \multirow[t]{3}{*}{ MixedTechnical } & 1 & 3,25 & 5 & 3 & 0,41 & 0,46 & 23,72 & 0,25 \\
\hline & 2 & $-83,68$ & 4 & 7 & $-7,61$ & $-1,03$ & 14,18 & 0,18 \\
\hline & 3 & 34,17 & 4 & 1 & 6,83 & 0,57 & 6,44 & 0,50 \\
\hline \multirow[t]{3}{*}{ BollingerPlus } & 1 & 10,10 & 5 & 2 & 1,44 & 0,64 & 18,29 & 0,51 \\
\hline & 2 & $-15,14$ & 3 & 5 & $-1,89$ & $-0,43$ & 7,83 & 0,34 \\
\hline & 3 & 25,48 & 5 & 2 & 3,64 & 0,29 & 11,87 & 0,42 \\
\hline \multirow[t]{3}{*}{ Fundamental } & 1 & 2,43 & 4 & 2 & 0,41 & 0,78 & 8,21 & 0,26 \\
\hline & 2 & $-21,75$ & 1 & 3 & $-5,44$ & 0,64 & 6,45 & 0,53 \\
\hline & 3 & 25,43 & 2 & 1 & 8,48 & 0,71 & 2,34 & 0,48 \\
\hline \multirow[t]{3}{*}{ Supervisor } & 1 & 2,26 & 3 & 1 & 0,57 & 0,82 & 2,47 & 0,48 \\
\hline & 2 & $-3,97$ & 2 & 1 & $-1,32$ & 0,73 & 1,98 & 0,56 \\
\hline & 3 & 21,30 & 3 & 0 & 7,10 & 0,94 & 2,90 & 0,59 \\
\hline \multirow[t]{3}{*}{ B \& H } & 1 & $-25,41$ & 0 & 1 & $-25,41$ & 0 & 0 & 0,11 \\
\hline & 2 & $-73,78$ & 0 & 1 & $-73,78$ & 0 & 0 & 0,08 \\
\hline & 3 & 13,63 & 1 & 0 & 13,63 & 0 & 0 & 0,22 \\
\hline
\end{tabular}

. On the basis of the research experiment one can draw the conclusion that integration of agents' knowledge enables selecting decisions which produce benefits satisfactory to a user. Integration of knowledge performed by the Supervisor agent using consensus determining algorithm is performed in a near to real time. The agent selects a final decision on the basis of suggestions generated by all remaining agents, which consequently leads to a decreased level of risk.

\section{CONCLUSION}

Functioning of a multi-agent decision support system for financial e-services requires continuous, automatic integration of agents' knowledge. The process enables the elimination of decisions generated by group members whose knowledge status has been evaluated as being poor, which means that decisions taken by such agents may most of the time bring unsatisfactory results. Thanks to that, their influence on the final decision established with the use of knowledge integration module and presented to a user is eliminated. Additionally developed algorithm enables taking into account summed-up knowledge of a group as it includes knowledge of all members of a group. The issues discussed in the paper imply further research concerning, for example, implementation of agents performing behavioural analysis and developing a multistep method of integration which would include improving knowledge of agents.

\section{REFERENCES}

[1] K. Dandapani, "Success and failure in web-based financial services", Communications of the ACM, 47(5), pp.31-33., 2004.

[2] PARP, Definicja e-finansów http://www.web.gov.pl/efinansowanie/76_141.html, (05.12.2015).

[3] J. Hu and N. Zhong, "A Multilevel Integration Approach for Developing E-Finance Portals: Challenges and Perspectives", in: Proceedings of the IEEE/WIC/ACM International Conference on Web
Intelligence (WI '07). IEEE Computer Society, Washington, DC, USA, 2007, pp. 825-828. DOI=http://dx.doi.org/10.1109/WI.2007.121.

[4] K. Narayanasamy, D. Rasiah and T. M. Tan, "The adoption and concerns of e-finance in Malaysia”, Electron. Commerce Res. 11 (4), 2011, pp. 383-400.

[5] A. Abroud, Y., V. Choong, S. Muthaiyah, D. Fie and G. Yong, "Adopting e-finance: decomposing the technology acceptance model for investors", Service Business 9 (1), 2015, pp. 161-182.

[6] P. Dyk and M. Lenar, "Applying negotiation methods to resolve conflicts in multi-agent environments", in: Multimedia and Network Information systems, MISSI 2006 Zgrzywa A. (ed.), Oficyna Wydawnicza PWr, Wrocław 2006.

[7] J.P. Barthlemy, "Dictatorial consensus function on n-trees", Mathematical Social Science, $\mathrm{nr}$ 25, 1992.

[8] M. Maleszka, B. Mianowska and N. T. Nguyen "A method for collaborative recommendation using knowledge integration tools and hierarchical structure of user profiles", Knowledge-Based Systems, Volume 47, pp. 1-13, 2013.

[9] M. Hernes and J. Sobieska-Karpińska, "Application of the consensus method in a multi-agent financial decision support system", Information Systems and e-Business Management 14 (1), Springer Berlin Heidelberg, 2016, DOI: $10.1007 / \mathrm{s} 10257-015-0280-9$.

[10] JADE Tutorial, http:/jade.tilab.com/doc/tutorials/JADEProgrammingTutorial-for-beginners.pdf (15.12.2015).

[11] J. Bollinger, Bollinger on Bollinger Bands, McGraw Hill, 2001.

[12] S. Franklin, F. G. Patterson, "The LIDA architecture: Adding new modes of learning to an intelligent, autonomous, software agent", in: Proceedings of the International Conference on Integrated Design and Process Technology. CA: Society for Design and Process Science, San Diego, 2006

[13] A. Bytniewski, M. Hernes, "Analiza opinii klientów o produkcie dokonywana w kognitywnym zintegrowanym systemie informatycznym zarządzania”, In: Porębska-Miąc, T., Sroka, H. (eds.), Systemy Wspomagania Organizacji. Katowice: Wydawnictwo Uniwersytetu Ekonomicznego w Katowicach, 2014.

[14] G. K. Świderska, W. Więcław (eds.), Sprawozdanie finansowe wedlug polskich $i$ międzynarodowych standardów rachunkowości. Difin/MAC sp. z o.o, Warszawa, 2012, p. 780

[15] J. Korczak, M. Hernes, M. Bac, "Performance evaluation of decisionmaking agents' in the multi-agent system", in: Proceedings of Federated Conference Computer Science and Information Systems (FedCSIS), Warszawa, 2014. 